\title{
A Review of Scientific Outputs on Spirituality and Depression Indexed in Important Databases
}

\author{
Jamile Mohammadi ${ }^{1}$, Kazem Rasoolzadeh Tabatabaei ${ }^{1}$, Masoud Janbozorgi ${ }^{*}$, Abbas Pasandideh ${ }^{3}$, Mahmood Salesi $^{4}$ \\ ${ }^{1}$ Department of Psychology, Faculty of Humanities, Tarbiat Modares University, Tehran, Iran \\ ${ }^{2}$ Department of Psychology, Research Institute of Howzah and University, Qom, Iran \\ ${ }^{3}$ Hadith Department, The University of Quran and Hadith, Qom, Iran \\ ${ }^{4}$ Chemical Injuries Research Center, Systems Biology and Poisonings Institute, Baqiyatallah University of Medical Sciences, Tehran, \\ Iran
}

Corresponding Author: Masoud Janbozorgi, Department of Psychology, Research Institute of Howzah and University, Qom, Iran. Tel: +98-9377693717, Email: psychjan@gmail.com

Received February 14, 2018; Accepted March 8, 2018; Online Published March 20, 2018

\begin{abstract}
Introduction: Depression is known as a mental disability. In recent years, interest in spirituality as a factor in decreasing depression symptoms has increased. The current study evaluated scientific articles on spirituality and depression indexed in the Scopus, PubMed, and Web of Science (WoS) databases.

Methods: This bibliometric review collected all articles on the subject of spirituality and depression published through 2016 from the Scopus, PubMed, and WoS databases. The citation counting period was until 13 September 2017. Data on the yearly trend, top-cited articles, most frequently cited journals, article type, multi-author collaboration, and international collaboration was collected from both articles from Iran and other countries.

Results: A total of 516 documents published by the end of 2016 were retrieved from the Scopus, PubMed, and WoS databases. The type of article most published was original article (355 (68.8\%) articles). The findings showed that the number of documents increased from 1 document in 1932 to 55 documents in 2016. Authors from the USA have produced approximately $60 \%$ of the documents published on this matter in the three searched databases, while Iran ranks second with $5.8 \%$ (32 documents) of the scientific articles published by the end of 2016. In these 516 articles, multi-author collaboration and international collaboration accounted for $80.7 \%$ and $10.6 \%$ of articles, respectively. The average number of citations per paper was $19.8(\mathrm{H}$-index $=47)$ and $14.6(\mathrm{H}$-index $=42)$ in the Scopus and WoS databases, respectively. These rates for Iranian articles were $2.9(\mathrm{H}$-index $=6)$ and $0.9(\mathrm{H}$-index $=3)$, respectively. Only 4 Iranian papers had been cited between 7 to 15 times; all other Iranian articles had been cited fewer than 4 times.

Conclusions: Iran has a low number of articles on spirituality and depression in the international indexes. As a religious and ideological country, Iran needs to increase its efforts to extend its spiritual and religious ideas on the international level. Establishing effective research networks that include other universities or countries and encouraging researchers and journals to focus on hot topics and international indexes are two approaches to managing future research in Iran.

Keywords: Spirituality, Depression, Bibliometrics

Citation: Mohammadi J, Rasoolzadeh Tabatabaei K, Janbozorgi M, Pasandideh A, Salesi M. A review of scientific outputs on spirituality and depression indexed in important databases. Int J Med Rev. 2018;5(1):41-46. doi:10.29252/IJMR-050107.
\end{abstract}

\section{Introduction}

Depression is a mental disability that can be categorized as mild, moderate, or severe, and it is an important cause of disability in diseases. This disability contributes to the increased global burden of disease. According to a 2012 report of the World Health Organization (WHO), depression is a cause for concern worldwide, and it is estimated that more than 350 million people of all ages suffer from depression. ${ }^{1}$

The prevalence of this disorder in the United States in the year 2000 was about $20 \%$ in women and $10 \%$ in men. ${ }^{2}$ The Center for Disease Control and Prevention (CDC) reported that the prevalence of depression is at least $10 \%$ among adults aged 18 years or older and about $45 \%$ in patients hospitalized with medical diseases. ${ }^{3}$ Concern about the effects of this disorder has increased the need for a solution to this global crisis. $^{4}$

In recent years, interest in spirituality as a factor in decreasing depression symptoms has increased., Various studies have indicated that higher levels of spirituality are associated with reduced symptoms of depression.,7-10

Religion, similar to spirituality, is known as a factor for coping and faster recovery from depression. ${ }^{11,12}$ Other researchers have shown that disappointment with God has a positive relationship with an increase in depression

Copyright $\odot 2018$ The Author(s). This is an open-access article distributed under the terms of the Creative Commons Attribution License (http:// creativecommons.org/licenses/by/4.0), which permits unrestricted use, distribution, and reproduction in any medium, provided the original work is properly cited. 
symptoms. ${ }^{13-15}$ Religious beliefs can also help people cope better with their physical conditions and, thus, indirectly reduce vulnerability to increasing depression. ${ }^{16}$

Conducting research and increasing the number of scientific outputs on this subject can help address challenges to the real impact of religion and spirituality on depression disorder. Bibliometrics is a statistical and mathematical method that can support research ${ }^{17}$ and present a more obvious and easier understanding of previous research. ${ }^{18}$

There is a lack of data about the bibliometrics of research outputs on the topic of spirituality and depression from Iran and the world in general. Thus, the current study evaluated simple bibliometrics from these scientific articles on spirituality and depression indexed in the Scopus, PubMed, and Web of Science (WoS) databases.

\section{Methods}

Data Collection and Search Strategy

This bibliometric investigation reviewed all types of articles published by the end of 2016 on the topic of spirituality and depression and indexed in the Scopus (https://www.scopus. com), PubMed (http://www.ncbi.nlm.nih.gov/pubmed), and WoS databases. These databases were selected because of their better coverage of results and investigation of citations. The search formula (TITLE (depressive OR depression) AND TITLE (religion OR religious OR spiritual OR spirituality OR Islam OR Islamic OR Quran)) was used in each of the three searched databases. After identifying the articles, the records retrieved from the three databases were merged, and duplicate records were removed. Then the relevant data was extracted from each included paper. Information on the indexing databases, year of publication, journal title, article type, number of authors, authors' country, and number of citations in each article (from Scopus and WoS) was extracted. The citation counting period was until 13 September 2017.
The journal impact factor of the Journal Citation Report (JCR), 2016, was used. Information on the authors' university was also extracted from articles associated with Iran. All procedures of this study were conducted by two reviewers. In cases of disagreement or uncertainty, e.g., regarding article type, the issue was discussed until a consensus was reached.

\section{Data Analysis}

The extracted data was imported into Microsoft Excel software 2010 and pre-processed. Then, it was transferred into IBM SPSS software, version 23, for analysis in the final stage. The number and percentage or mean were reported to descriptive of articles according to the extracted parameters. The parameters of yearly trend, top-cited articles, and frequency of journals were reported as tables and figures. Two types of collaboration, multi-author collaboration and international collaboration, were also examined. The multiauthor collaboration rate is defined as the rate of documents coauthored by more than one author, and articles written by authors from different countries were classified as the international collaboration rate. $^{19}$

\section{Results}

After searching the three databases and removing all duplicate records, a total of 516 documents published by the end of 2016 were retrieved. The findings showed that 390 (75.6\%), 260 (50.4\%), and 393 (76.2\%) articles were indexed in Scopus, PubMed, and WoS, respectively (Figure 1).

The most frequent article type was original articles with 355 (68.8\%) papers indexed, followed by meeting abstracts and conference papers with $97(18.8 \%)$, review articles with 19 (3.7\%), letters and notes with $11(2.1 \%)$, short surveys with 8 (1.5\%), book reviews with $7(1.4 \%)$, corrections and erratum with $6(1.2 \%)$, and editorials with $4(0.8 \%)$ papers published during this period (Table 1).

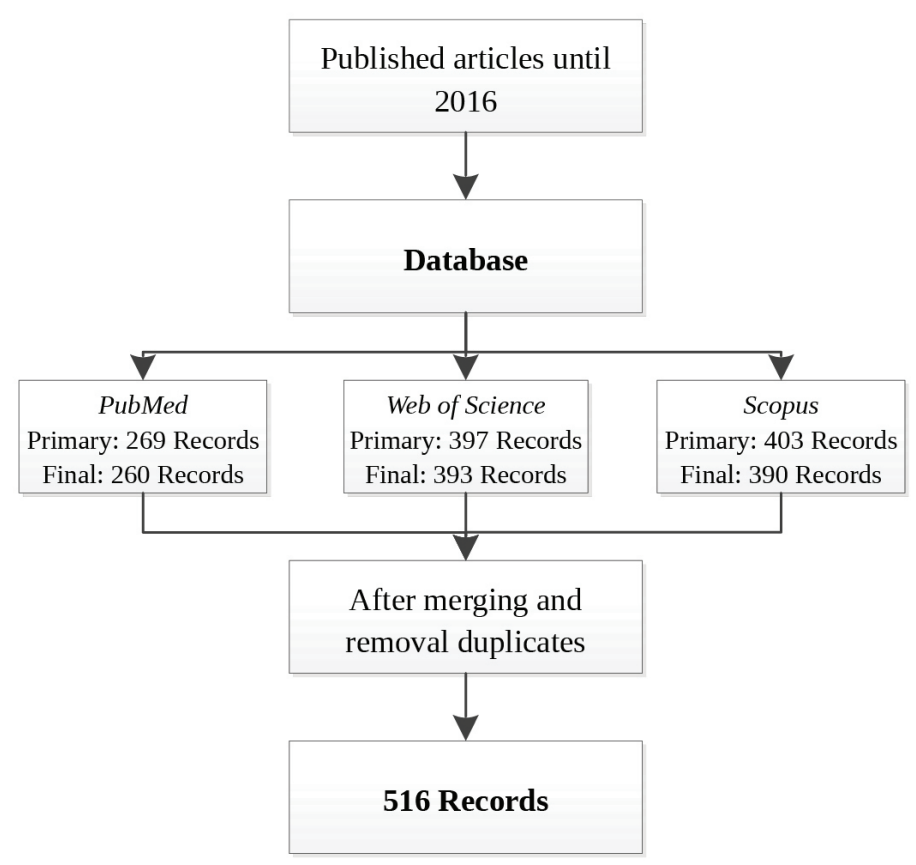

Figure 1. Tracking and Enrollment of Articles. 
Table 1. Distribution of Articles Based on Type

\begin{tabular}{lll}
\hline Article type & No. & Percent \\
\hline Article & 355 & 68.8 \\
Review & 19 & 3.7 \\
Book Review & 7 & 1.4 \\
Meeting Abstract and Conference Paper & 97 & 18.8 \\
Short Survey & 8 & 1.5 \\
Correction, Erratum & 6 & 1.2 \\
Editorial & 4 & .8 \\
Letter, Note & 11 & 2.1 \\
\hline
\end{tabular}

Figure 2 presents the annual number of documents published by the end of 2016. The overall trend is incremental, indicating that in the past decade (2007-2016), the number of publications on spirituality and depression have obviously increased, such that more than half $(51.2 \%)$ of the papers on this topic were produced after 2010. The first paper on spirituality and depression was published in 1932. The year 2016, with 55 (10.7\%) documents published, had the highest frequency of scientific articles (Figure 2).

The most productive country in spirituality and depression research was the USA which is ranked first in number of publications with 304 (58.9\%) records. Iran is ranked second with $30(5.8 \%)$ papers published, followed by the UK with 20 (3.9\%), Canada with 17 (3.3\%), and the Netherlands with 16 (3.1\%) papers published (Table 2).

The findings also indicated that the majority of publications on spirituality and depression research were written by several authors (mean number of authors $=3.8$ ). The multiauthor collaboration rate was $80.7 \%$, and the international collaboration rate was $10.6 \%$. In other words, only $10 \%$ of articles were written by authors from at least two different countries.

Table 3 shows the top-ranking journals in terms of number of articles published (28.5\%). The largest number of articles was published in Gerontologist [25 (4.8\%)], followed by the Journal of Religion and Health [16 (3.1\%)], Mental Health, Religion, and Culture [14 (2.7\%)], and the Journal of General Internal Medicine [13 (2.5\%)]. These 4 journals all belong to the USA (Table 3).

Total number of citations for these documents in Scopus and WoS databases are 7730 (per article=19.8, H-index=47) and 5761 (per article=14.6, H-index=42), respectively.
Table 2. Frequency of Country of Author

\begin{tabular}{lcc}
\hline Country & No. & Percent \\
\hline Australia & 7 & 1.4 \\
Canada & 17 & 3.3 \\
Finland & 4 & .7 \\
France & 6 & 1.2 \\
Greece & 8 & 1.5 \\
India & 5 & 1 \\
Iran & 30 & 5.8 \\
Japan & 8 & 1.5 \\
Malaysia & 4 & .7 \\
Netherlands & 16 & 3.1 \\
South Korea & 14 & 2.7 \\
Taiwan & 4 & .7 \\
\hline UK & 20 & 3.9 \\
\hline USA & 304 & 58.9 \\
\hline
\end{tabular}

Table 3. Frequency of Journals

\begin{tabular}{lccc}
\hline Journal & No. (\%) & $\begin{array}{c}\text { IF } \\
(\mathbf{2 0 1 6})\end{array}$ & Country \\
\hline American Journal of Geriatric Psychiatry & $8(1.5)$ & 2.87 & USA \\
American Journal of Psychiatry & $7(1.4)$ & 14.18 & USA \\
Annals of Behavioral Medicine & $12(2.3)$ & 2.98 & USA \\
Gerontologist & $25(4.8)$ & 3.51 & USA \\
International Journal of Psychology & $8(1.5)$ & 1.78 & USA \\
Journal of Affective Disorders & $8(1.5)$ & 3.43 & Netherlands \\
Journal of General Internal Medicine & $13(2.5)$ & 3.70 & USA \\
Journal of Nervous and Mental Disease & $11(2.1)$ & 1.86 & USA \\
Journal of Religion \& Health & $16(3.1)$ & 0.87 & USA \\
Mental Health, Religion and Culture & $14(2.7)$ & - & USA \\
Psychology of Religion and Spirituality & $7(1.4)$ & 2.00 & USA \\
Psychosomatic Medicine & $8(1.5)$ & 3.86 & USA \\
Southern Medical Journal & $10(1.9)$ & 0.93 & USA \\
\hline
\end{tabular}

According to WoS, the self-citation rate in this field is $9.7 \%$ (562 citations). The 12 top-cited articles are shown in Table 4. The maximum number of citations in Scopus was 372 and in WoS was 320 for top papers. All 12 of the top-cited papers belonged to the USA. The first 3 top-cited articles with more than 200 citations were published in 1992 (Table 4).

Iranian authors have produced only $5.8 \%$ of all articles on the subject of spirituality and depression. Table 5 shows

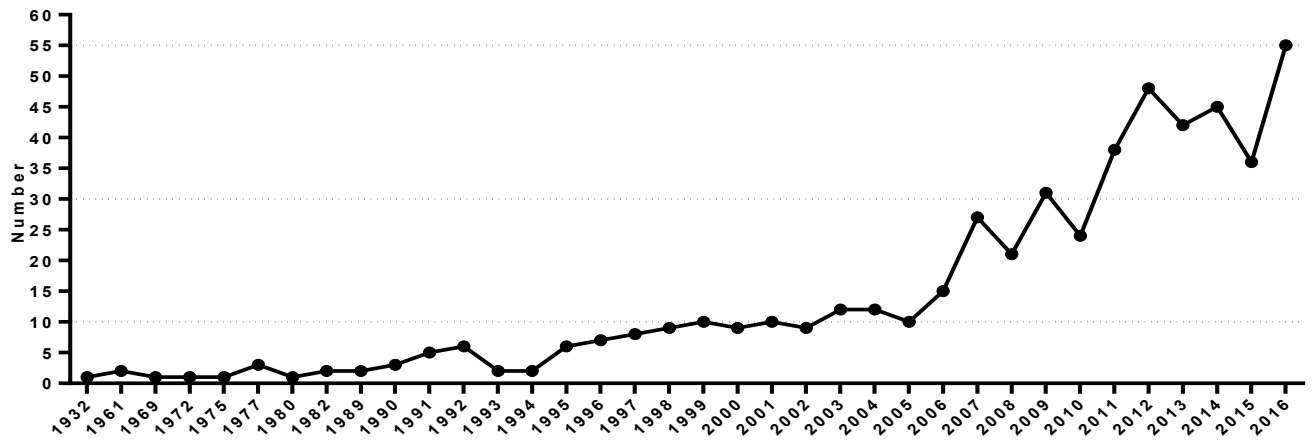

Figure 2. Number of Documents. 
Table 4. Twelve Top-Cited Articles

\begin{tabular}{|c|c|c|c|c|}
\hline Article & Year & Scopus & WoS & Journal \\
\hline Religious coping and depression among elderly, hospitalized, medically ill men & 1992 USA & 372 & 320 & American Journal of Psychiatry \\
\hline Religion, Disability, Depression, and the Timing of Death & 1992 USA & - & 206 & American Journal of Sociology \\
\hline $\begin{array}{l}\text { Comparative efficacy of religious and nonreligious cognitive-behavioral therapy } \\
\text { for the treatment of clinical depression in religious individuals }\end{array}$ & 1992 USA & 246 & 205 & $\begin{array}{l}\text { Journal of Consulting and Clinical } \\
\text { Psychology }\end{array}$ \\
\hline Spirituality, religion, and depression in the terminally ill & 2002 USA & 220 & 161 & Psychosomatics \\
\hline $\begin{array}{l}\text { Spiritual well-being, religiosity, hope, depression, and other mood states in } \\
\text { elderly people coping with cancer }\end{array}$ & 1997 USA & 190 & & Oncology Nursing Forum \\
\hline $\begin{array}{l}\text { Religious belief, depression, and ambulation status in elderly women with broken } \\
\text { hips }\end{array}$ & 1990 USA & 182 & 157 & American Journal of Psychiatry \\
\hline $\begin{array}{l}\text { Guilt, discord, and alienation: The role of religious strain in depression and } \\
\text { suicidality }\end{array}$ & 2000 USA & 185 & 176 & Journal of Clinical Psychology \\
\hline $\begin{array}{l}\text { Modeling the cross-sectional relationships between religion, physical health, } \\
\text { social support, and depressive symptoms }\end{array}$ & 1997 USA & 171 & 150 & American Journal of Geriatric Psychiatry \\
\hline $\begin{array}{l}\text { Race, religious involvement and depressive symptomatology in a southeastern } \\
\text { U.S. community }\end{array}$ & 1995 USA & 164 & 135 & Social Science and Medicine \\
\hline Religion and depression: A review of the literature & 1995 USA & 156 & & Twin Research \\
\hline $\begin{array}{l}\text { Religious activity and depression among community-dwelling elderly persons } \\
\text { with cancer: The moderating effect of race }\end{array}$ & 1998 USA & 121 & 82 & Journals of Gerontology Series B \\
\hline $\begin{array}{l}\text { Psychosocial factors in outcomes of heart surgery: The impact of religious } \\
\text { involvement and depressive symptoms }\end{array}$ & 2004 USA & 105 & 87 & Health Psychology \\
\hline
\end{tabular}

Table 5. Distribution of Articles from Iranian Universities

\begin{tabular}{|c|c|}
\hline University & No. \\
\hline Allame Tabatabai University & 2 \\
\hline Birjand University & 1 \\
\hline Baqiyatallah University of Medical Sciences & 1 \\
\hline Isfahan University of Medical Sciences & 1 \\
\hline Ilam University of Medical Sciences & 2 \\
\hline Islamic Azad University, Roudehen Branch & 1 \\
\hline Hormozgan University & 1 \\
\hline Islamic Azad University, Sari Branch & 1 \\
\hline Islamic Azad University, Karaj Branch & 1 \\
\hline Islamic Azad University, Science and Research Branch & 2 \\
\hline Islamic Azad University, Central Tehran Branch & 1 \\
\hline Islamic Azad University, Saveh Branch & 1 \\
\hline Lorestan University of Medical Sciences & 1 \\
\hline Iran University & 2 \\
\hline Isfahan University & 4 \\
\hline Islamic Azad Univ, Ahwaz & 2 \\
\hline Islamic Azad Univ, Tehran & 1 \\
\hline Mashhad University & 1 \\
\hline Mazandaran University & 1 \\
\hline Payame Noor University, Tehran & 1 \\
\hline Qazvin University of Medical Sciences & 1 \\
\hline Qazvin University & 1 \\
\hline Shiraz University & 2 \\
\hline Shahed University & 2 \\
\hline Shahid Chamran University & 1 \\
\hline Shahid Bahonar University & 1 \\
\hline Shahid Beheshti University & 1 \\
\hline Shahid Beheshti University of Medical Sciences & 1 \\
\hline Shahid Rajaee University & 3 \\
\hline Tehran University & 3 \\
\hline Tehran University of Medical Sciences & 2 \\
\hline Tabriz University & 2 \\
\hline University of Kashan & 1 \\
\hline Zanjan University & 1 \\
\hline Zahedan University of Medical Sciences & 1 \\
\hline
\end{tabular}

the lists of universities of Iran, 35 of which, each with a maximum of 4 articles, have contributed to the increase in publications. Isfahan University had the most publications among universities (Table 5). The total number of citations for Iranian papers in the Scopus and WoS databases are 73 (per article $=2.9, \mathrm{H}$-index $=6$ ) and 22 (per article=0.9, $\mathrm{H}$-index=3), respectively. Only 4 Iranian papers have received between 7 and 15 citations; all others had fewer than 4 citations (Table 6).

\section{Discussion}

To survey scientific articles on the topic of spirituality and depression was the major purpose of the current study. The findings of this study will lead to a better understanding of the current status of Iran and the world. The findings indicated that about 516 documents were published in the Scopus, PubMed, and WoS databases, $68.8 \%$ of which were original articles; only 3.8 were published as review articles. The current findings showed an annual growth in the number of published papers, increasing it from 1 in 1932 to 55 in 2016. This incremental trend is reasonable and similar to other fields in science. The growth pattern represented a slow growth rate from 1932 to 2010 followed by a major increase in the growth rate with almost half of the papers published after 2010 .

In 2012, Koenig conducted a meta-analytic review on research on this subject through 2010. He retrieved 414 observational studies and found that 253 (61\%) of them showed a significant relationship between greater levels of religion and spirituality and lower levels of depression. ${ }^{12}$ His results were similar to those of the current study, with the difference being that the current study searched only three important databases were searched and performed a bibliometric analysis; Koenig aimed to identify the correlation between spirituality and depression.

For a series of publications, collaboration is often measured by the average number of authors per paper. For the topic of spirituality and depression, this figure is 3.8 authors per article. 
Table 6. Four Top-cited Articles in Affiliation with Iran

\begin{tabular}{|c|c|c|c|c|}
\hline Article (University) & Year & Scopus & WoS & Journal \\
\hline $\begin{array}{l}\text { Religious and spiritual factors in depression: Review and integration of the } \\
\text { research (Ilam University of Medical Sciences) }\end{array}$ & 2012 & 17 & - & Depression Research and Treatment \\
\hline $\begin{array}{l}\text { Religious vs. conventional cognitive behavioral therapy for major depression in } \\
\text { persons with chronic medical illness: A pilot randomized trial (Shahid Beheshti } \\
\text { University of Medical Sciences) }\end{array}$ & 2015 & 10 & 10 & Journal of Nervous and Mental Disease \\
\hline $\begin{array}{l}\text { Correlation between religious coping and depression in cancer patients (Birjand } \\
\text { University of Medical Sciences) }\end{array}$ & 2013 & 8 & 5 & Psychiatria Danubina \\
\hline $\begin{array}{l}\text { Investigating the relation of depression and religious coping and social support } \\
\text { in women with breast cancer (Shiraz \& Isfahan University of Medical Sciences) }\end{array}$ & 2011 & 7 & - & Journal of Isfahan Medical School \\
\hline
\end{tabular}

The current study also reported the details of collaboration, i.e. multi-author and international collaborations with $80.7 \%$ and $10.6 \%$, respectively. These rates are lower than those in other areas of research not only in the world, but also in Iran. For example, Yu et al evaluated collaborative behavior in CHD research retrieved from the Web of Science database. Their results showed that the average number of authors per paper and percentages of multi-authored and multi-national publications in 2010 were $6.4,93 \%$, and $19 \%$, respectively. ${ }^{19}$ The average number of authors per article on obstructive sleep apnea (OSA) was 5. ${ }^{20}$ Farahani et al showed that in the WoS database, Iranian multi-author and international collaborations in cardiovascular articles published from 2002 to 2011 were $94 \%$ and $17 \%$, respectively. ${ }^{21}$

It is a given that collaboration, especially international collaboration, is an important factor in increasing the quality of a study ${ }^{22,23}$ and will lead to the paper being cited more frequently. ${ }^{24}$ Currently, the average number of citations per paper on the subject of spirituality and depression was 19.8 $(\mathrm{H}$-index=47) in Scopus and $14.6(\mathrm{H}$-index $=42)$ in WoS. Zyoud showed that papers on calcium channel blockers received an average of 9.1 citations per article. ${ }^{25}$ The $\mathrm{H}$-index of tobacco use research activities in Middle Eastern Arab (MEA) countries is 34 with 9.95 citations per article in the Scopus database up through $2014 .{ }^{26}$ The number of citations for these articles is appropriate and comparable, but it can be improved by increasing the number of collaborations, especially international ones.

According to the current results, by the end of 2016, authors from the United States had produced approximately $60 \%$ of the articles on spirituality and depression in the three named databases, while Iran is ranked second with 5.8\% (32 papers) publications. Iranian authors were scattered among 35 universities. All of the publications were of different types, and no English-language book review of Iranian publications was found on these three databases. These articles had on average 2.9 and 0.9 citations per article in the Scopus and WoS databases, respectively. Thus, the current survey showed that, compared with the total number of scientific publications in the world, Iran has a low quota and a low number of citations. These findings seem not to be consistent with reality. In other words, given the religious situation and the activities of researchers in Iran, the wide gap between Iran and the United States was unexpected in terms of the number of documents. One reason for this may be that the papers of Iranian researchers on this subject are more often published in Persian, and Iranian authors compared to researchers of other fields have less of a tendency to publish in journals with international indexes. Moreover, Iranian journals in this field are not indexed in Scopus, PubMed, or WoS; therefore, publications pertaining to the topic of spirituality and depression in these non-indexed journals are less seen and counted.

\section{Conclusions}

The current study provides a global description of publications on the topic of spirituality and depression. Iran has a low quota of articles with international indexes. As a religious and ideological country, Iran needs to increase its efforts to extend its spiritual and religious ideas on the international level. Establishing effective research networks that include different universities or countries to promote quality of scientific documents, encouraging researchers to focus on highly-cited topics in this field and to publish their papers in journals with international indexes, and creating the policy among Iranian journals in the field of spirituality to upgrade the index of journals are approaches that will increase the visibility of Iranian authors worldwide and can be considered in the future management of Iranian research.

\section{Authors' Contributions}

All authors contributed equally to this study.

\section{Conflict of Interest Disclosures}

The authors declare they have no conflicts of interest.

\section{Acknowledgments}

This study is part of a research toward a Ph.D. degree at the Faculty of Humanities, Tarbiat Modares University, and it was financially supported by this university. The authors extend their appreciation to the university for its support.

\section{References}

1. World Health Organization (WHO). Depression, a hidden burden: Let's recognize and deal with it. WHO website. http://www. who.int/entity/mental_health/management/depression/flyer_ depression_2012.pdf?ua=1. Published 2012.

2. Steffens DC, Skoog I, Norton MC, et al. Prevalence of depression and its treatment in an elderly population: the Cache County study. Arch Gen Psychiatry. 2000;57(6):601-607. doi:10.1001/ archpsyc.57.6.601.

3. Steffens DC, Blazer DG. Mood disorders. In: Blazer DG, Steffens DC, eds. Essentials of Geriatric Psychiatry. 2nd ed. Washington, DC: American Psychiatric Publishing; 2012:125-148. 
4. Marcus M, Yasamy MT, van Ommeren M, Chisholm D, Saxena S. Depression: A global public health concern. http://www.who.int/ mental_health/management/depression/who_paper_depression_ wfmh_2012.pdf. Published 2012.

5. Koenig HG. Religion, spirituality, and health: the research and clinical implications. ISRN Psychiatry. 2012;2012:278730. doi:10.5402/2012/278730.

6. Walsh F. Strengthening family resilience. 2nd ed. New York: The Guilford Press; 2015.

7. Brown DR, Carney JS, Parrish MS, Klem JL. Assessing spirituality: The relationship between spirituality and mental health. J Spiritual Ment Health. 2013;15(2):107-122. doi:10.1080/19349637.2013. 776442 .

8. Hill PC, Pargament KI. Advances in the conceptualization and measurement of religion and spirituality: Implications for physical and mental health research. Psycholog Relig Spiritual. 2008;S(1):317. doi:10.1037/1941-1022.S.1.3.

9. Vieten C, Scammell S, Pilato R, Ammondson I, Pargament KI, Lukoff D. Spiritual and religious competencies for psychologists. Psycholog Relig Spiritual. 2013;5(3):129-144. doi:10.1037/ a0032699.

10. Exline JJ, Prince-Paul M, Root BL, Peereboom KS. The spiritual struggle of anger toward God: a study with family members of hospice patients. J Palliat Med. 2013;16(4):369-375. doi:10.1089/ jpm.2012.0246.

11. Koenig HG. Depression in chronic illness: does religion help? J Christ Nurs.2014;31(1):40-46.doi:10.1097/cnj.0000000000000016.

12. Koenig HG, King DE, Carson VB. Handbook of Religion and Health. 2nd ed. New York, NY: Oxford University Press; 2012:145173 .

13. Sandage SJ, Williamson I. Relational spirituality and dispositional forgiveness: a structural equations model. J Psychol Theol. 2010;38(4):255-266. doi:10.1177/009164711003800403.

14. Strelan P, Acton C, Patrick K. Disappointment with god and well-being: The mediating influence of relationship quality and dispositional forgiveness. Couns Values. 2009;53(3):202-213. doi:10.1002/j.2161-007X.2009.tb00126.x.

15. Levin J. Is depressed affect a function of one's relationship with God?: Findings from a study of primary care patients. Int J Psychiatry Med. 2002;32(4):379-393. doi:10.2190/3183-wpyv-
$3 k y y-k 3 v 7$.

16. Koenig HG, Larson DB, Larson SS. Religion and coping with serious medical illness. Ann Pharmacother. 2001;35(3):352-359. doi:10.1345/aph.10215.

17. Riviera E. Mapping scientific literature: Structuring scientific communities through scientometrics [dissertation]. Milan: Department of Sociology, University of Bicocca; 2011-2012.

18. Wallace DP, Van Fleet CJ. Knowledge into Action: Research and Evaluation in Library and Information Science: Research and Evaluation in Library and Information Science. ABC-CLIO; 2012.

19. Yu Q, Shao H, He P, Duan Z. World scientific collaboration in coronary heart disease research. Int J Cardiol. 2013;167(3):631639. doi:10.1016/j.ijcard.2012.09.134.

20. Huamani C, Rey de Castro J, Gonzalez-Alcaide G, Polesel DN, Tufik S, Andersen ML. Scientific research in obstructive sleep apnea syndrome: bibliometric analysis in SCOPUS, 1991-2012. Sleep Breath. 2015;19(1):109-114. doi:10.1007/s11325-0140969-x.

21. Shahrabi Farahani H, Eskrootchi R, Mohaghegh N, Hosseini AF. A study of scientific collaboration in Iranian cardiovascular articles in web of science; 2002-2011. Journal of Health Administration. 2014;17(56):46-55.

22. Persson O. Are highly cited papers more international? Scientometrics. 2010;83(2):397-401. doi:10.1007/s11192-0090007-0

23. van den Besselaar $\mathrm{P}$, Hemlin S, van der Weijden I. Collaboration and competition in research. High Educ Policy. 2012;25(3):263266. doi:10.1057/hep.2012.16.

24. Cronin B, Shaw D. Citation, funding acknowledgement and author nationality relationships in four information science journals. J Doc. 1999;55(4):402-408. doi:10.1108/EUM0000000007153.

25. Zyoud SH, Al-Jabi SW, Sweileh WM, Waring WS. Scientific research related to calcium channel blockers poisoning: Bibliometric analysis in Scopus, 1968-2012. Hum Exp Toxicol. 2015;34(11):1162-1170. doi:10.1177/0960327115571768.

26. Zyoud SH, Al-Jabi SW, Sweileh WM, Awang R. A Scopus-based examination of tobacco use publications in Middle Eastern Arab countries during the period 2003-2012. Harm Reduct J. 2014;11:14. doi:10.1186/1477-7517-11-14. 